\title{
Effect of Nutritional Therapy on Acne Vulgaris among Adolescent Students
}

\author{
Noura Ahmed Abd El-Ghaffar ${ }^{1}$, Ebtisam Mohamed Abd El-Aal ${ }^{2}$ and Taiseer Hamido \\ Abosree $^{3}$
}

(1) Nursing Specialist in Menouf Public Hospital, (2) Professor of Community Health Nursing, Faculty of Nursing, Benha University, and (3) Lecturer of Community Health Nursing, Faculty of Nursing, Benha University.

\begin{abstract}
Background: Acne vulgaris is a common disease that affects the majority of the adolescent students and a large number of young adults. Aim of study was to evaluate the effect of nutritional therapy on acne vulgaris among adolescent students. Research design: Quasi experimental research design (pre and post-test) was utilized to conduct this study. Setting: The study was carried out in all Faculties of Benha University including 15 Faculty. Sample: Convenient sample of the University students (first year) in the previous mentioned facilities, the total sample included 280 students. Tools of data collection: A structured interviewing questionnaire, which covers the following parts: 1) demographic data and medical history of the adolescent students. 2) Knowledge about acne vulgaris. 3) Reported practices about daily care of acne vulgaris and nutritional therapy practices regarding acne vulgaris. Results: $55.7 \%$ of them were female, and $66.4 \%$ of them lived in rural. $40.0 \%$ of the adolescent students affected with acne vulgaris for less than one year, $39.3 \%$ of them had oily skin, $55.7 \%$ of them had apparent pimples and $46.4 \%$ of them had acne vulgaris in full face. $38.6 \%$ of the adolescent students had good knowledge in pre-nutritional therapy construction and then this percentage increased to $81.8 \%$ post-nutritional therapy construction, and $67.5 \%$ of the adolescent students had unsatisfactory practices pre-nutritional therapy construction which decreased to $28.6 \%$ post nutritional therapy construction. Conclusion: The nutritional therapy construction succeeded to improve the students' knowledge and practices daily care. There was positive correlation between total knowledge scores of the adolescent students, total reported practices scores and nutritional therapy scores of them pre and post nutritional therapy construction. Recommendations: Develop and implement health education program for adolescent students to increase their knowledge about acne vulgaris and their practices to manage acne vulgaris, educational program to determine the effect of diet on development and severity on acne vulgaris. Further researches are needed to implement nutritional therapy on adolescent students to eat a healthy food to prevent acne vulgaris.
\end{abstract}

\section{Keywords: Acne vulgaris, Adolescent students, Nutritional therapy}

\section{Introduction:}

Adolescence is the period of development that begins at puberty and ends in early adulthood. Adolescence period is ranged from (10-24 years). Adolescence is characterized by a rapid pace of growth that is second only to that of infancy. Nutrition and the adolescent transition are closely intertwined, since eating patterns and behaviors are influenced by many factors, including peer influences, parental modeling, food availability, food preferences, cost, convenience, personal and cultural beliefs, mass media, and body image. Diet has been a 
part of the acne vulgaris discussion for decades. Several studies have evaluated the significance of the glycemic index of various foods and glycemic load in adolescents with acne vulgaris, demonstrating individuals with acne who consume diets with a low glycemic load have reduced acne lesions compared with individuals on high glycemic load diets (Baldwin \& Tan, 2020).

Acne vulgaris (AV) is the most common skin condition affecting late adolescents across the world. AV affects $85 \%$ of young adults aged 12-25 years. AV consistently represents the top three most prevalent skin conditions in the general population. The production of androgens during puberty explains in part why acne vulgaris is so prevalent in this population regardless of socioeconomic status and nationality (Lynn et al., 2016).

Nutritional therapy is a potential treatment for acne because it plays very important role in control on condition. The diet affected on acne vulgaris characterized by high amounts of sugary desserts, refined grains, high protein, high-fat dairy products, and highsugar drinks. As students in the late adolescence become more independent, the freedom to choose what and where to eat. Conversely, there are also populations documented that abstain from unhealthy diet, eating meals low in meat and avoid of grains or dairy products. As a result, acne vulgaris is absent in these populations (Lynn et al., 2016).

Community Health Nurse (CHN) has an important role in management of acne vulgaris. CHN educating adolescent students about reasonable expectations, a medication regimen with multiple agents and treatmentrelated side effects can maximize both adherence and efficacy and educates adolescent students to avoid picking at acne is necessary because this may lead to scarring. CHN should provide guidance about appropriate hygiene, including gentle, twicedaily skin washing with a mild, nondrying soap and use of oil-free non-comedogenic moisturizer and sunscreen and educates adolescent students about the need to wash hair regularly and avoid frequent handling of the skin. Cosmetics should be oil-free and eat healthy diet filled with fruits and vegetables (Afif et al., 2019).

\section{Significance of the study}

Acne vulgaris is a common heath problem affecting adolescents with considerable impact on their quality of life. Acne vulgaris consistently represents the top three most prevalent skin conditions in the general population. The prevalence of acne vulgaris in Egypt was $34.7 \%$; acne vulgaris is more common among females than males $(50.3 \%)$ females and males (49.7\%) (Abdel Fadl, 2018).

Aim of the study: The aim of the study was to evaluate the effect of nutritional therapy on acne vulgaris among adolescent students.

\section{Research Hyposis:-}

Nutritional therapy will improve the management of acne vulgaris among adolescent students.

\section{Research design}

A quasi experimental design was utilized to fulfill the study.

\section{Setting:-}

This study was conducted at all Faculties in Benha University including 15 Faculties,

\section{Sample:}

Convenient sample of the first year students with acne vulgaris was used in this study. 


\section{Sample size:-}

Total sample of adolescent students with acne vulgaris at Benha University was (280).

\section{Tools}

\section{One tool was used for data collection:}

Tool I: A structured interviewing questionnaire

A structured interviewing questionnaire was developed by the researcher based on literature review under the supervision of supervisors, and written in a simple clear Arabic language consisted of three parts:

\section{First part:}

A. It was concerned with demographic data of adolescent students. It consists 9 items (Faculty name, age, sex, residence, marital status, occupation, mother occupation, mothers `level of education and smoking).

B. It was concerned with medical history of the adolescent students. It consists of 8 items (duration, skin type, form, sites, effects from acne vulgaris, had the student taken treatment for acne vulgaris before, type of treatment and other skin disease which the student suffer from).

\section{Second part:}

It was concerned with adolescent students' knowledge about acne vulgaris. It was include 13 questions (meaning, causes, signs, and types of acne vulgaris, signs of inflamed acne, and signs of non-inflamed acne, degree, risk factors, complications, and places of acne vulgaris in the body, age stage most affected with acne vulgaris, prevention and treatment of acne vulgaris).

\section{Scoring system:}

The scoring system for nurses' knowledge was calculated as follows 2 score for complete and correct answer, while 1 score for incomplete and correct answer, and 0 for incorrect or don't know answer. For each area of knowledge, the score of the items was summed-up and the total was divided by the number of the items, giving a mean score for the part. These scores were converted into a present score. The total knowledge score was considered good if the score of the total knowledge $\geq 75 \%$, while considered average if it is equal to $50-<75 \%$, and considered poor if it is $<50 \%$.

- Good $\rightarrow$ if the score of the total knowledge $>75 \%(>19.5)$

- Average $\rightarrow$ if it equals $50-75 \%$ (1319.5)

- Poor if it is $\rightarrow<50 \%(<13)$

\section{Third part:}

A- It was concerned with adolescent students' reported practices about daily care of acne vulgaris. It was consist of personal hygiene, treatment and smoking.

Personal hygiene reported practices which include 8 practices (wash face twice daily, use appropriate lotion, use suitable moisturizer daily, scrub the face twice weekly, use sun block, dry the face with boiled cotton towel, avoid face contact with unclean hands and wash hands before and after contact with acne vulgaris).

Treatment reported practices which include 7 items (take medication on time, use ointments and creams as directed by doctor continuously, avoid sun exposure after using ointments and creams, avoid messing with pimples to prevent scars, avoid squeezing pimples and itching, avoid stress, get enough sleep).

Smoking reported practices which include 2 practices (avoid smoking and caffeine like coffee and avoid passive smoking).

\section{Scoring system}

Each item has 2 levels of answer done and not done. These were respectively scored 1 and 0 . For each area of reported practices, 
the score of the items was summed- up and the total divided by the number of the items, giving a mean score for the part. The total score of the adolescent students regarding total reported practices pre and post program was classified into the following:

- Satisfactory $\rightarrow$ when the total score of practices was $>80 \%(>13.6)$

- Un satisfactory $\rightarrow$ when the total score of practices was $<80 \%(<13.6)$

B- It was concerned with nutritional therapy practices regarding acne vulgaris. It consisted of (allowed types of food and restricted types of food).

C- 1) Allowed types of food consisted of (eat vegetables, eat fruits that don't contain salts, drink plenty of water, eat beans such as beans and lentils, eat nuts, eat foods that contain vitamin A such as sweet potatoes, apricots, and ban, eat foods that contain omega 3 such as salmon, mackerel, and soybeans, eat foods that contain vitamin B6 such as beef, tuna, beans and turkey, eat foods that contain vitamin $\mathrm{E}$ such as spinach, avocado, olive oil and almond, eat foods that contain zinc such as spinach, wheat germ, chicken, beans and mushrooms, eat foods that contain selenium such as tuna, sardines and beef, eat foods that contain chromium such as broccoli, lettuce, onion, orange juice, yeast, wheat germ and green beans, drink ginger daily, eat basil regularly, eat foods with high fibers such as whole grains, vegetables and fruits specially in shell and eat fig and its products).

D- 2) Restricted types of foods which contain (eat chocolates, drink bottled juices, eat sugars and starches, drink soda, eat foods with high salts such as salted popcorn, processed meats and canned foods, drink dairy and its products such as milk and ice cream, eat fruits with high salts such as mango and strawberry, eat high fat foods, eat fried foods and eat peanuts and its products).

\section{Scoring system of nutritional therapy practices:}

Nutritional therapy practices had 3 levels of answers in large quantities, in small quantities and avoid it. These were respectively scored 2,1 , and 0 . For each area of nutritional therapy practices, the score of the items was summed- up and the total divided by the number of the items, giving a mean score for the part. The total score of the adolescent students regarding nutritional therapy practices pre and post program was classified into:

- Compliance $\rightarrow$ when the total score of practices was $>80 \%(>41.6)$

- Incompliance $\rightarrow$ when the total score of practices was $<80 \%(<41.6)$

\section{Ethical consideration:}

Permission has been obtained orally from each adolescent student before conducting the interview and given a brief orientation to the purpose of the study. They were also reassured that all information gathered would be confidential and used only for the purpose of the study. No names were required on the forms to ensure anonymity and confidentiality. They were also informed about their right to withdraw at any time from the study without giving any reasons.

\section{Content validity:}

The tools were reviewed for comprehensiveness, appropriateness and legibility by five experts of Faculties Nursing Staff from the Community Specialties. The experts ascertained the face and content validity of the tools.

\section{Reliability:}

The reliability was done by Cronbach's Alpha coefficient test which revealed that each of the two tools consisted of relatively homogeneous items as indicated by the moderate to high reliability of each tool. The internal consistency of knowledge was 0.88 , 
practice was 0.25 and nutritional therapy was 0.68 .

\section{Preparatory phase:}

Preparation of the study design and data collection tools was based on reviewing current and past available national and international related literatures, and the theoretical knowledge of various aspects of the study using textbooks, articles, magazines and internet search. This was necessary for the researcher to be acquainted with and oriented about aspects of the research problem as well as assist in the development of the data collections tools.

\section{Pilot study}

A pilot study was conducted on $10 \%$ of the studied adolescent students (28 students) to test the content, applicability and simplicity of the tool. Based on the pilot study the tools were organized. Organization of the tool included rephrasing, rearrangement of some questions. After refinement and organization final forms of the tool were developed. This pilot study was carried in two weeks before starting the study and those who shared in the pilot study were included in the studied sample.

\section{Nutritional therapy construction:}

Nutritional therapy construction was designed by the researcher after reviewing the related literature. It was implemented through three phases:

\section{Preparatory phase:}

Based on the results obtained from the interviewing questionnaire, as well literature review, nutritional therapy construction was developed by the researcher. It was implemented immediately after pre-test.

General objective: Evaluate the effect of nutritional therapy on acne vulgaris among adolescent students.
Content of nutritional therapy construction: The content of nutritional therapy was designed to meet adolescent students with acne vulgaris needs. Its contents were meaning, causes, signs, types and signs of inflamed and non-inflamed acne vulgaris. Degree, risk factors, complications and sites of acne vulgaris in the body. Age stage which most affected with acne vulgaris, prevention and treatment of acne vulgaris. Practices of the adolescent student's about daily care routine of acne vulgaris such as personal hygiene, treatment and smoking. Nutritional therapy practices which include (allowed foods and restricted foods).

\section{Teaching methods:}

All adolescent students received the same nutritional therapy construction content using the same teaching methods, there were Lectures / discussion.

Teaching aids: Suitable teaching aids were specially prepared for nutritional therapy construction, as follows: Booklets, pictures and handout.

Phase (II): Implementation of the nutritional therapy nutritional therapy construction: Data were collected over 9 months from the start of March 2019 to end of November 2019; the study was conducted by the researcher for the studied sample in the selected settings at all Faculties of Benha University. The researcher visited each Faculty 2 days per/week (Saturday and Tuesday) from 10:00 am to 2:00 pm according to the attendance of adolescent students. The researcher explained the purpose and importance of the study to the adolescent students and obtained their consent. The number of sessions was 6 sessions of 3 hours (4 theoretical sessions and 2 practical sessions; 2 hours theoretical and 1 
hour practical). The duration of each session was 30-40 minutes, including periods of discussion. The researcher collected data from the adolescent students through filling the sheet. The average numbers of interviewing adolescent students was between 10-12 student/day depending on their response to the interviewers. The nutritional therapy construction was implemented for the adolescent students at the suitable time for them, to insure that they were exposed to the same learning experience, they received the same of the first session, and orientation to the nutritional therapy construction and its process were presented. Each session started with a summary about what had been given through the previous session, then the objectives of the new topics, taking into consideration the use of simple language. Discussion, motivation and reinforcement during nutritional therapy construction session were used to enhance learning. Direct reinforcement in the form, a copy of the nutritional therapy construction was given as a gift for each adolescent student to use it as future reference. All the participants were cooperative with the researcher. At the end of each session, adolescent students participated in a discussion to correct any misunderstanding. Also, they were informed about the time of next session.

\section{Phase (III): Evaluation of the nutritional} therapy: Evaluation of the nutritional therapy construction was done by using the post - test questionnaire which was the same formats of pre- test in order to compare the change in the adolescent students' knowledge and practices immediately after implementation of nutritional therapy construction

\section{Statistical analysis}

Statistical presentation and analysis of the present study data were carried out, using mean, Chi- square and linear correlation coefficient (r) by using the Statistical Package for Social Science (SPSS version 21). Significance level was considered as follows: Highly statistically significant $\mathrm{P}<$ $0.001^{* *}$ statistically significant $\mathrm{P}<0.05^{*}$ Not significant $\mathrm{P}>0.05$

\section{Results:}

Table 1: Shows the demographic data of the studied adolescent students. It was clear that $63.9 \%$ of the studied adolescent students their age were 18 years old with mean $17.91 \pm 0.59,55.7 \%$ of them were female, and $66.4 \%$ of them lived in rural. $96.1 \%$ of the studied adolescent students were single, 83.9 $\%$ of them were studying only. Regarding mothers' occupation $56.1 \%$ of them were housewives and $48.6 \%$ of them had secondary education. Concerning smoking $92.9 \%$ of the studied adolescent students were nonsmoking.

Table (2): Reveals that $40.0 \%$ of the studied adolescent students affected with acne vulgaris for less than one year, $39.3 \%$ of them had oily skin, and $55.7 \%$ of them had apparent pimples. Regarding site of acne vulgaris $46.4 \%$ of the studied adolescent students had acne vulgaris in full face and $53.6 \%$ of them had severe effects from acne vulgaris. Regarding treatment of acne vulgaris $60.0 \%$ of the studied adolescent students took drugs before, $56.8 \%$ of the studied adolescent students used topical creams and $66.8 \%$ of them hadn't other skin diseases.

Fig (1): Illustrates that $38.6 \%$ of the studied adolescent students had good total knowledge scores about acne vulgaris in pre-nutritional therapy construction, and then this percentage increased to $81.8 \%$ during post-nutritional therapy construction. 
Table (3): Shows that there was highly statistically significant relation between total knowledge scores of the studied adolescent students regarding acne vulgaris and age of them at pre nutritional therapy construction phase, and there was statistically significant difference between total knowledge scores of the studied adolescent students and their marital status at pre-nutritional therapy construction. In addition, there was no significant relation between total knowledge scores of the studied adolescent students and their residence and sex at pre-nutritional therapy construction phase.

Table (4): Shows that there was positive correlation between total knowledge scores of the studied adolescent students, total reported practices and nutritional therapy of them during pre and post nutritional therapy construction.

Table (1): Distribution of the studied adolescent students regarding their demographic data $(\mathbf{n}=\mathbf{2 8 0})$.

\begin{tabular}{|c|c|c|}
\hline Demographic data & No & $\%$ \\
\hline \multicolumn{3}{|l|}{ Age } \\
\hline 17 & 63 & 22.5 \\
\hline 18 & 179 & 63.9 \\
\hline 19 & 38 & 13.6 \\
\hline \multicolumn{3}{|l|}{ Mean \pm SD $17.91 \pm 0.59$} \\
\hline \multicolumn{3}{|l|}{ Sex } \\
\hline Male & 124 & 44.3 \\
\hline Female & 156 & 55.7 \\
\hline \multicolumn{3}{|l|}{ Residence } \\
\hline Rural & 186 & 66.4 \\
\hline Urban & 94 & 33.6 \\
\hline \multicolumn{3}{|l|}{ Marital status } \\
\hline Single & 269 & 96.1 \\
\hline Married & 11 & 3.9 \\
\hline \multicolumn{3}{|l|}{ Occupation } \\
\hline Studying and working beside the study & 45 & 16.1 \\
\hline Studying only & 235 & 83.9 \\
\hline \multicolumn{3}{|l|}{ Mothers' occupation } \\
\hline Employee & 102 & 36.4 \\
\hline House wife & 157 & 56.1 \\
\hline Free business & 21 & 7.5 \\
\hline \multicolumn{3}{|l|}{ Mothers' education level } \\
\hline Can't read and write & 12 & 4.3 \\
\hline Read and write & 26 & 9.3 \\
\hline Primary education & 25 & 8.9 \\
\hline Secondary education & 136 & 48.6 \\
\hline University education & 81 & 28.9 \\
\hline \multicolumn{3}{|l|}{ Smoking } \\
\hline Smoking & 20 & 7.1 \\
\hline Non smoking & 260 & 92.9 \\
\hline
\end{tabular}


Table (2): Distribution of the studied adolescent students regarding their medical history $(\mathbf{n}=\mathbf{2 8 0})$.

\begin{tabular}{|c|c|c|}
\hline Medical history & No & $\%$ \\
\hline \multicolumn{3}{|c|}{ Duration of acne vulgaris } \\
\hline Less than 1 year & 112 & 40.0 \\
\hline $1-2$ year & 63 & 22.5 \\
\hline $2-3$ year & 41 & 14.6 \\
\hline More than 3 years & 64 & 22.9 \\
\hline \multicolumn{3}{|l|}{ Skin type } \\
\hline Dry & 25 & 8.9 \\
\hline Mixed & 78 & 27.9 \\
\hline Oily & 110 & 39.3 \\
\hline Don't know & 67 & 23.9 \\
\hline \multicolumn{3}{|c|}{ Forms of acne vulgaris } \\
\hline Apparent pimples & 156 & 55.7 \\
\hline Pimples contain pus & 74 & 26.4 \\
\hline Scars & 50 & 17.9 \\
\hline \multicolumn{3}{|l|}{ Sites of acne vulgaris } \\
\hline Full face & 130 & 46.4 \\
\hline Chin & 25 & 8.9 \\
\hline Shoulder & 87 & 31.1 \\
\hline Forehead & 78 & 27.9 \\
\hline Cheeks & 59 & 21.1 \\
\hline Chest & 5 & 1.8 \\
\hline \multicolumn{3}{|c|}{ Effects from acne vulgaris } \\
\hline Mild & 34 & 12.1 \\
\hline Moderate & 48 & 17.1 \\
\hline Severe & 150 & 53.6 \\
\hline There is no & 48 & 17.3 \\
\hline \multicolumn{3}{|c|}{ Treatment for acne vulgaris before? } \\
\hline Yes & 168 & 60.0 \\
\hline No & 112 & 40.0 \\
\hline \multicolumn{3}{|l|}{ Type of treatment? } \\
\hline Topical creams & 159 & 56.8 \\
\hline Laser & 6 & 2.1 \\
\hline Natural recipes & 22 & 7.9 \\
\hline Oral tablets & 62 & 22.1 \\
\hline Chemical peeling & 7 & 2.5 \\
\hline There is no & 112 & 40.0 \\
\hline \multicolumn{3}{|c|}{ Other skin diseases which suffer from } \\
\hline Skin allergy & 59 & 21.1 \\
\hline \multirow[t]{2}{*}{ Food allergy } & 41 & 14.6 \\
\hline & 187 & 66.8 \\
\hline
\end{tabular}




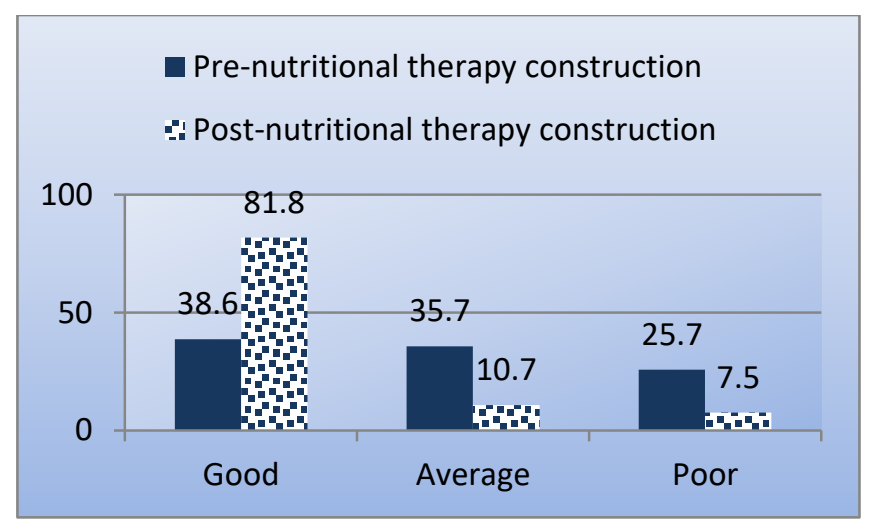

Fig (1): Percentage distribution of studied adolescent students regarding total knowledge scores about acne vulgaris pre/post nutritional therapy construction $(\mathbf{n}=\mathbf{2 8 0})$

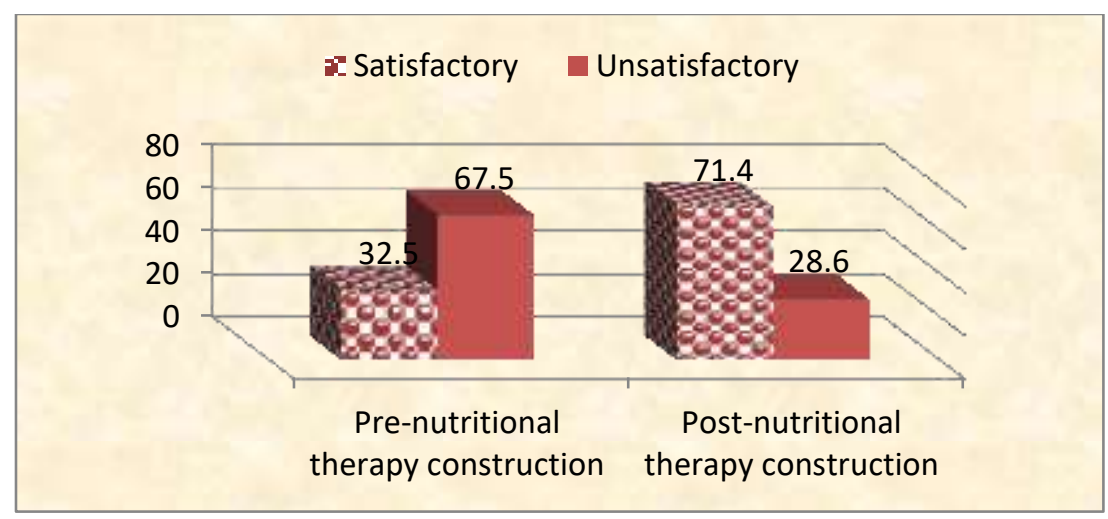

Fig (2): Percentage distribution of studied adolescent students regarding total reported practices scores of daily care pre/post nutritional therapy construction $(n=280)$

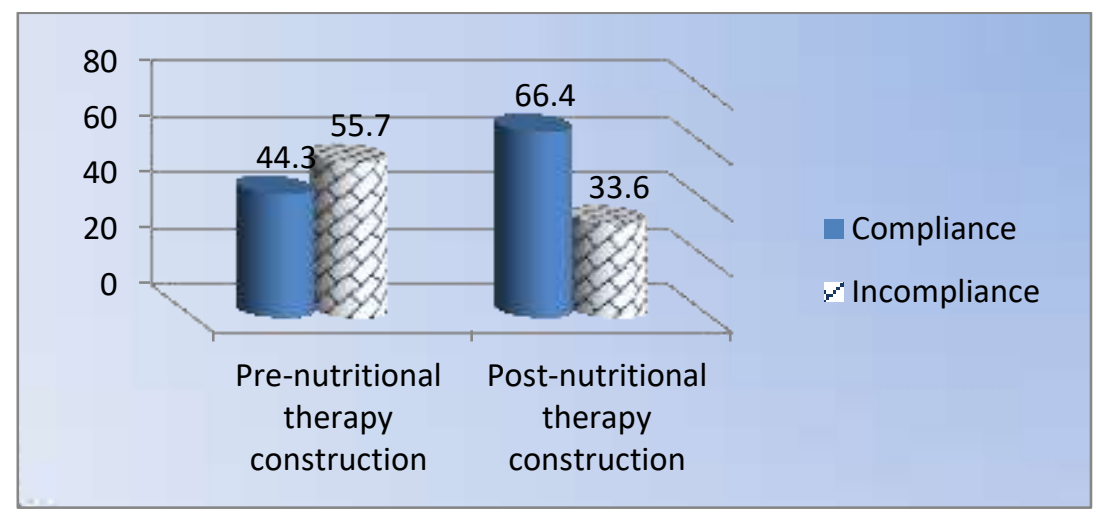

Fig (3): Percentage distribution of studied adolescent students regarding total nutritional therapy scores pre/post nutritional therapy construction $(n=280)$ 
Table (3): Relation between total knowledge score and studied adolescent student's demographic data pre and post nutritional therapy construction $(\mathbf{n}=\mathbf{2 8 0})$

\section{Total knowledge scores}

\begin{tabular}{|c|c|c|c|c|c|c|c|c|c|c|}
\hline \multirow{2}{*}{$\begin{array}{l}\text { Demographic } \\
\text { data }\end{array}$} & \multicolumn{2}{|c|}{$\begin{array}{l}\text { Pre- nutritional } \\
\text { construction }\end{array}$} & therapy & \multirow[t]{2}{*}{$X^{2}$} & \multirow{2}{*}{$\begin{array}{l}\mathrm{p}- \\
\text { value }\end{array}$} & \multicolumn{3}{|c|}{$\begin{array}{l}\text { Post nutritional } \\
\text { construction }\end{array}$} & \multirow[t]{2}{*}{$X^{2}$} & \multirow{2}{*}{$\begin{array}{l}\mathrm{p}- \\
\text { value }\end{array}$} \\
\hline & $\begin{array}{l}\text { Poor } \\
(\mathrm{n}=72) \\
\%\end{array}$ & $\begin{array}{l}\text { Average } \\
(n=100) \\
\%\end{array}$ & $\begin{array}{l}\text { Good } \\
(n=108) \\
\%\end{array}$ & & & $\begin{array}{l}\text { Poor } \\
(\mathrm{n}=21) \\
\%\end{array}$ & $\begin{array}{l}\text { Average } \\
(\mathrm{n}=30) \\
\%\end{array}$ & $\begin{array}{l}\text { Good } \\
(n=229) \\
\%\end{array}$ & & \\
\hline \multicolumn{11}{|l|}{ Age } \\
\hline 17 & 25.0 & 21.0 & 22.2 & 32.67 & $\begin{array}{l}<0.001 \\
* *\end{array}$ & 38.1 & 23.3 & 21.0 & 4.71 & 0.318 \\
\hline 18 & 68.1 & 76.0 & 50.0 & & & 52.4 & 70.0 & 64.2 & & \\
\hline 19 & 6.9 & 3.0 & 27.8 & & & 9.5 & 6.7 & 14.8 & & \\
\hline \multicolumn{11}{|l|}{ Sex } \\
\hline Male & 50.0 & 48.0 & 37.0 & 3.81 & 0.149 & 42.9 & 56.7 & 42.8 & 2.08 & 0.352 \\
\hline Female & 50.0 & 52.0 & 63.0 & & & 57.1 & 43.3 & 57.2 & & \\
\hline \multicolumn{11}{|l|}{ Residence } \\
\hline Rural & 62.5 & 69.0 & 66.7 & 0.798 & 0.671 & 81.0 & 53.3 & 66.8 & 4.308 & 0.116 \\
\hline Urban & 37.5 & 31.0 & 33.3 & & & 19.0 & 46.7 & 33.2 & & \\
\hline \multicolumn{11}{|l|}{ Marital status } \\
\hline Single & 100.0 & 98.0 & 91.7 & 9.482 & $<0.05^{*}$ & 100.0 & 96.7 & 95.6 & 1.003 & 0.605 \\
\hline Married & 0.0 & 2.0 & 8.3 & & & 0.0 & 3.3 & 4.4 & & \\
\hline
\end{tabular}

*Statistically significant difference $\mathbf{p} \leq \mathbf{0 . 0 5} \quad * *$ Highly significant difference $\mathbf{p} \leq \mathbf{0 . 0 0 1}$

Table (4): Correlation between total knowledge scores, total reported practices and nutritional therapy pre and post nutritional therapy construction $(n=280)$

\begin{tabular}{lllll}
\hline Items & $\begin{array}{l}\text { Total knowledge } \\
\text { Pre-nutritional } \\
\text { construction }\end{array}$ & therapy & $\begin{array}{l}\text { Post } \\
\text { construction }\end{array}$ & nutritional \\
& $\mathbf{R}$ & p-value & $\mathbf{R}$ & p-value \\
\hline Total reported practices & 0.152 & $.011^{*}$ & 0.122 & $0.042^{*}$ \\
Total nutritional therapy & 0.001 & .983 & 0.014 & 0.818 \\
\hline
\end{tabular}

*Statistically significant difference $\mathbf{p} \leq 0.05 * *$ Highly significant difference $\mathbf{p} \leq \mathbf{0 . 0 0 1}$

\section{Discussion}

Regarding to the demographic data of the studied adolescent students, the current study showed that, more than half of the studied adolescent students' age were 18 years old with mean $17.91 \pm 0.59$ and the most of them were single, more than half of them were female, two thirds of them lived in rural area and the majority of them were studying only. More than half of the studied adolescent students' mothers were housewives, less than half of them had secondary school and most of the adolescent students were nonsmoker 
Concerning medical history of studied adolescent students, the present study revealed that more than one third of studied adolescent students were affected with acne vulgaris for less than one year. This might be due to they just reached to adolescent stage. This result agreed with Alanazi et al. (2018), who assessed "Prevalence and psychological impact of acne vulgaris among female Secondary School students in Arar City, Saudi Arabia, in 2018", $(\mathrm{n}=718)$, and reported that approximately $40 \%$ of the students were affected less than one year.

The current study revealed that more than one third of the studied adolescent students had oily skin. This result agreed with Colletti, (2019), who studied "Depression risk in the treatment of moderate to severe acne with isotretinoin in India" ( $n=340)$, and reported that approximately $40 \%$ of secondary school students had oily skin. This might be due to oily skin is the most type affected with acne vulgaris.

The current study revealed that more than half of studied adolescent students had apparent pimples. This result disagreed with Hazarika \& Rajaprabha (2016), who studied the "Assessment of life quality index among patients above 15 years old with acne vulgaris in a Suburban Population" $(n=410)$, and reported that more than half of the patients above 15 years old had acne scars. This might be due bad life style of the students as eating unhealthy diet.

In the present study, less than half of the studied students had acne vulgaris in full face. This result agreed with Andrea et al. (2016), who studied the "Guidelines of care for management of acne vulgaris in American adult population" $(\mathrm{n}=114)$, who reported that $65.2 \%$ of the adult population had facial lesions and grade II acne were most common. This might be due to the face is the most area exposing to the sun.

The current study revealed that more than half of the studied students had chronic dermatologic effects from acne vulgaris. This result agreed with Hazarika \& Archana (2016), who studied "The psychosocial impact of acne vulgaris in India" ( $n=100)$, and reported that $75 \%$ of the patient above 15 years with acne vulgaris had post acne chronic effects. This might be due to the students squeeze the pimples and itching them.

The current study revealed that less than two thirds of the studied students took drugs before. This result agreed with Broussard \& Marshall, (2019), who studied "Acne vulgaris: Diagnosis and treatment, the current scenario in India" ( $\mathrm{n}=150)$, and reported that more than $70 \%$ of the sample had taken local treatment for acne lesions. This might be due to their interesting with their appearance.

This study showed that, more than half of the studied adolescent students used topical creams. This result agreed with Oge et al. (2019), who studied " Acne Vulgaris: Diagnosis and treatment in Loisiana state" $(\mathrm{n}=$ 185 ), and reported that $65 \%$ of the studied young patients with acne vulgaris used topical creams in treatment of acne vulgaris. This might be due to topical creams is the most safe and easy type of medication.

The current study showed that, approximately two thirds of the studied adolescent students hadn't other skin diseases. This result agreed with Duarte, (2019), who studied "New and emerging drugs for the treatment of acne vulgaris in adolescents in USA" $(n=260)$, and reported that 


\section{Effect of Nutritional Therapy on Acne Vulgaris among Adolescent Students}

approximately $73.3 \%$ of the studied adolescent sample hadn't other skin diseases.

Regarding total knowledge scores of acne vulgaris, the current study revealed that less than two fifths of the studied adolescent students had good total knowledge scores about acne vulgaris during pre-nutritional therapy construction and the majority of them had good knowledge post nutritional therapy construction. This result agreed with Albahlol et al., (2017), who studied the "Knowledge, attitude and practice toward acne vulgaris among community adolescents in Jeddah city" $(n=461)$, and reported that $59.1 \%$ of the community adolescent had good level of knowledge toward acne vulgaris. This might be due to the effect of the nutritional therapy construction on the studied adolescent students' knowledge.

Regarding total practices scores, the current study revealed that less than one third of the studied adolescent students had satisfactory practices about total personal hygiene during pre-nutritional therapy construction. This result agreed with Ghanem et al., (2020), who studied "Knowledge, attitudes, and practices of secondary school students toward the management of acne vulgaris in Palestine" $(n=270)$, and reported that only $20 \%$ of the students had satisfactory practice regarding daily care of acne vulgaris. While this percentage increased to less than three quarters of the adolescent students during post nutritional therapy construction. According to Robert, (2015), who stated that skin hygiene is important in diminishing severity of acne vulgaris. This might be due to they are busy with many other things and not organizing their time.

In the current study, more than half of the studied adolescent students had incompliance total nutritional therapy scores during pre-nutritional therapy construction. While this result decreased to approximately one third of the students after post nutritional therapy construction. This result agreed with Mullaaziz et al., (2019), who studied "Evaluation of the use of complementary and alternative therapy in patients with psoriasis and acne vulgaris in Isparta, Turkey", $(n=300)$, and reported that $72.7 \%$ of young patients had poor knowledge about diet therapy and its effect on acne vulgaris at preevaluation and $35.1 \%$ of them post evaluation. This might be due to lack of awareness about the effect of food on acne vulgaris, whether in the negative or in the affirmative.

As regards relation between the studied adolescent students total knowledge score and their demographic data, the present study showed that there was highly statistical significant relation between total knowledge score of the studied adolescent students and their age at pre nutritional therapy construction. This result agreed with Hazarika and Rajaprabha (2016), who reported that there were statistically significance relation between level of knowledge about acne vulgaris and age of the studied patients above 15 years old. This might be due to the students in this age stay along time in front of media and internet and may be acquired knowledge about acne vulgaris.

The present study showed that there was statistically significant difference between total knowledge score of the studied adolescent students and their marital status at pre-nutritional therapy construction. This might be due to most of the students were single. This result agreed with Mohamed et al. (2019), who studied "Prevalence and 
disability induced by acne vulgaris among adolescent students at secondary school in Assiut city", $(n=1026)$, and reported that there was statistically relation between knowledge of the students and marital status.

The present study showed that there was no statistical significant relation between total knowledge score of the studied adolescent students and their sex prenutritional therapy construction. This result disagreed with Albahlool et al., (2017), who reported that there was statistically significance relation between level of knowledge about acne vulgaris and gender of the studied adult female. This might be due to both of sex are interested in acquiring knowledge about acne vulgaris to control it.

Concerning correlation between total knowledge score, total reported practices of the studied adolescent students and nutritional therapy construction, the present study showed that there were positive correlation between total knowledge scores of the studied adolescent students, their total reported practices scores and nutritional therapy practices pre and post nutritional therapy construction (table 4). This result was in the same line with Mullaaziz et al., (2019), who reported that there was statistically correlation between knowledge, practices and nutritional therapy of the studied students. This result also was at the same line with the study made by Alghamdi et al., (2017), who studied "Effect of milk and dairy products consumption on acne risk and severity in young adult patients with acne vulgaris attending the dermatology clinics at King Fahd hospital of the University in Alkhobar, Saudi Arabia", $(n=100)$, and reported that there was positive correlation between level of knowledge of the studied University students and food affecting on acne vulgaris. This might be due to attributed to the fact that the knowledge was the baseline of practices and which affect positively on their practices of nutritional therapy.

\section{Conclusion}

More than half of the adolescent students their aged were 18 years with mean 17.91 \pm 0.59 . More than one third of the adolescent students had good total knowledge scores about acne vulgaris in pre-nutritional therapy construction compared by majority of them at post nutritional therapy construction. More than two thirds of the adolescent students had unsatisfactory reported practices scores regarding acne vulgaris during prenutritional therapy construction which decreased to less than one third of them during post nutritional therapy construction. More than one half of the adolescent students had incompliance answers regarding total nutritional therapy scores during prenutritional therapy construction, which decreased to approximately one third of them post nutritional therapy construction. There was positive correlation between total knowledge scores, total reported practices scores and total nutritional therapy scores of the adolescent students during pre and post nutritional therapy construction.

\section{Recommendations}

- Develop and implement health educational program for adolescent students to increase their knowledge about acne vulgaris and their practices to manage acne vulgaris.

- Further researches are needed to implement nutritional therapy on adolescent to encourage them to eat a healthy food to prevent acne vulgaris. 


\section{Effect of Nutritional Therapy on Acne Vulgaris among Adolescent Students}

\section{Refrences:}

Abdel Fadl, N. (2018). Acne vulgaris: Prevalence, severity and impact on quality of life and self-esteem among secondary schoolaged adolescents in Egypt. Journal of pediatric care; 22(2): 73-84.

Afifi, T., El-Ashmawy, A. and ElFakharany, N. (2019). Evaluation of the therapeutic diet for enhancement of acne status. Journal of national nutrition institute; 51(1): 19-38.

Alanazi, M., Hammad, S. and Mohamed, A. (2018). Prevalence and psychological impact of Acne vulgaris among female secondary school students in Arar city, Saudi Arabia. Elecrtonic physician journal; 10(8): 7224-7229.

Albahlol, A., Alshotairy, H., Abdullah, R., Fouad, B., Tariq, S. and Malky, A. (2017). Assessment of knowledge, attitude and practice toward acne vulgaris among community in Jeddah. The Egyptian journal of hospital medicine; 66(1): 193-197.

Alghamdi, H., Alhemel, A. and Bukhari, I. (2017). Effect of milk and dairy products consumption on acne risk and severity in young adult patients with acne vulgaris attending the dermatology clinics at King Fahd hospital of the university in Alkhobar, Saudi Arabia. Journal of scientific science; 4(12): 114-120.

Andrea, L., Arun, L., Bethanee, J., Alikhan, A., Hilary, E., Diane, S., whitney, P., Emmy, M. and Jonnette, E. (2016). Guidelines of care for the management of acne vulgaris. Journal of the American Academy of Dermatology; 74(5): 945-973.

Baldwin, H. and Tan, J. (2020). Effect of diet on acne and its response to treatment.
American journal of clinical dermatology; 124(4): 205-211.

Broussard, A. and Marshall, M. (2019). Acne vulgaris: Diagnosis and treatment. Journal of American family physician; 100(8): 475-484.

Colletti, T. (2019). Depression risk in the treatment of moderate to severe acne with isotretinoin. Journal of medical science; 1(2): 114.

Duarte, I. (2019). New and emerging drugs for the treatment of acne vulgaris in adolescents. Journal of expert opinion on pharmacotherapy; 20(8): 1009-1024.

Ghanem, R., Mostafa, S., Abu Hamada, N. and Khdour, M. (2020). Knowledge, attitudes, and practices of community pharmacists toward the management of acne vulgaris in Palestine: A cross-sectional study. International journal of dermatology; 59(4): 506-512.

Hazarika, N. and Archana, M. (2016). The Psychosocial impact of acne vulgaris. Indian journal of dermatology; 61(5): 515-520.

Hazarika, N. and Rajaprabha, R. (2016). Assessment of life quality index among patients with acne vulgaris in a suburban population. Indian journal of dermatology; 61(2): 163-168.

Lynn, D., Umari, T., James, A., Dunnick, C. and Dellvalle, R. (2016).Adolescence health medical therapy, $7^{\text {th }}$ ed., Elseiver publication, America, Pp.13-25.

Mullaaziz, D., Baysal, V. and Erturan, L. (2019). Evaluation of the use of complementary and alternative therapy in 
patients with psoriasis and acne vulgaris. Turkish journal of dermatology; 53(4): 60.

Oge, L., Broussard, A., and Marshall, M. (2019). Acne vulgaris: Diagnosis and treatment. Journal of American family physician; 100(8): 475-484.
Robert, J. (2015). Management of acne vulgaris. Journal of pediatric Health care; 25(5): 235. 


\section{تأثثر العلاج الغذائي على حب الثباب الثائع بين الطلاب المراهقين \\ نورا احمد عبدالغفار - إبتسام محمه عبدالعال - تيسير حميدو ابوسريع}

يعتبر حب الثباب مرض شائع يصيب غالبية الطلاب المر اهقين وعدد كبير من الثباب. لذلك هدفت هذه الدراسة الي تقييم تأثير العلاج الغذائي على حب الثباب بين الطلاب المراهقين. حيث تم استخدام تصميم بحث شبه تجريبي (قبل وبعد الاختبار) لإجر اء هذه الدر اسة. وأجريت هذه الدر اسة في جميع كليات جامعة بنها بما في ذلك

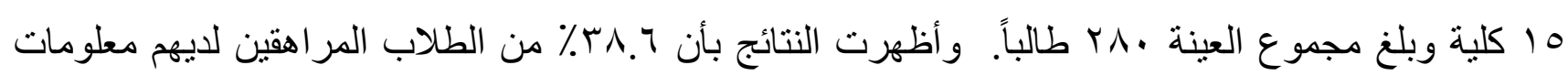

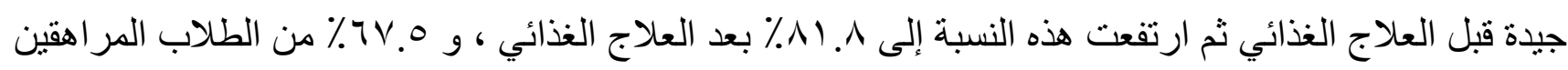

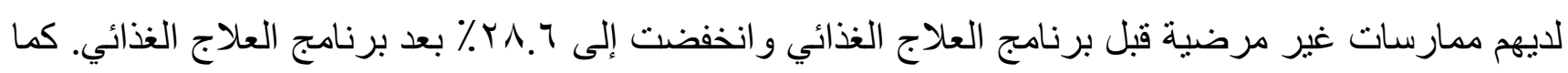
نجح برنامج العلاج الغذائي في تحسين معلومات وممارسات الرعاية اليومية للطلاب. كما أوصت الدراسة بتطوير وتتفيذ برنامج التثقف الصحي للطلاب المر اهقين لزيادة معرفتهم حول حب الثباب الثائع وممارساتهم للر عايه اليومية. 